\title{
Infection of Multipotent IL-3-dependent Stem Cells With a Retroviral Vector Containing the IL-3 Gene Confers Density- dependent Growth Autonomy Without Blocking Differentiation*
}

\author{
U. Just ${ }^{4}$, E. Spooncer ${ }^{1}$, M. Katsuno ${ }^{1}$, I. Hampson ${ }^{1}$, M. Dexter ${ }^{1}$, J.F. DeLamarter ${ }^{3}$, \\ C. Stocking ${ }^{2}$, N. Kluge ${ }^{2}$, and W. Ostertag ${ }^{2}$
}

\section{A. Introduction}

It is widely accepted that most naturally occurring leukemias are monoclonally derived from multipotent stem cells $[5-7,17]$, but the genetic changes leading to their transformation are poorly understood. A useful system in which to study the various processes occurring during leukemogenesis is offered by nonleukemic, multipotent stem cell lines (FDCPmix) established from murine long-term marrow cultures [20]. These cells grow continuously in vitro in the presence of Il-3, but they can also be induced to differentiate into mature granulocytes, macrophages, erythrocytes, and occasionally megakaryocytes, eosinophils, and mast cells by serum factors [20] or in association with marrow stromal cells [20] or certain embryonic mesenchymal cell lines [18]. Recent data have shown that hematopoietic growth-fac-

1 Paterson Institute for Cancer Research, Christie Hospital and Holt Radium Institute, Manchester, M20 9BX, United Kingdom

2 Heinrich-Pette-Institut für Experimentelle Virologie und Immunologie an der Universität Hamburg, Martinistraße 52, 2000 Hamburg 20, FRG

3 Biogen, 46 Route des Acacias, 1227 Geneva, Switzerland

4 Present address: Universitätskrankenhaus Eppendorf, II. Medizinische Klinik, Abteilung für Klinische Chemie, Martinistr. 52, D-2000 Hamburg 20, FRG

* This work was supported by the Cancer Research Campaign, United Kingdom, and the Deutsche Forschungsgemeinschaft. The Heinrich-Pette-Institut is financially supported by the Free Hanseatic City of Hamburg and the Bundesministerium für Jugend, Familie, Frauen und Gesundheit tor-dependent progenitor cell lines acquire growth-factor-independent growth and tumorigenicity when they are infected with retroviral vectors containing genes coding for Il-3 or GM-CSF [10, 11]. However, these studies have been restricted to cell lines which are blocked in differentiation and may therefore not reflect the alterations that occur in stem cells during leukemogenesis. To determine the effects of aberrant expression of Il-3 in differentiation-inducible stem cells we infected FDCPmix cells with a selectable retroviral vector carrying the cDNA of Il-3.

\section{B. Materials and Methods}

\section{Vector Construction} and Virus-producing Cell Lines

A cDNA clone of Il-3 (kindly provided by N. Gough, Melbourne) was subcloned into the MPSV-based M3neo vector $[9,10]$ and used for transfections into the amphotropic helper cell line, PA 317 [16], to produce infectious $\mathrm{M} 3 \mathrm{MuV}$ particles. Cell clone psi $2 \operatorname{mos}^{-1}$ no. 4 containing the neo MPSV mos deletion vector [22] was used to infect PA 317 in order to obtain amphotropic pseudotypes necessary for the infection of the ecotropicvirus producing FDCPmix cell lines [23]. Cell clones with titres of $10^{3}-10^{5}$ for $\mathrm{MuV}$ and $10^{5}-10^{8} \mathrm{GTU}$ for $\operatorname{mos}^{-1}$ and with intact proviral genomes were used for co-cultivation experiments.

\section{Cells}

Virus-producing cell lines were kept in minimal essential medium supplemented 
with $10 \%$ fetal calf serum. Hematopoietic cell lines were maintained in Iscove's modified Dulbecco's medium, supplemented with $20 \%$ horse serum and Wehi 3BD-conditioned medium (WEHI CM) as a source of multi-CSF (Il-3) at a concentration that stimulated optimal cell growth.

\section{Viral Infection and Selection Procedure}

$10^{5}$ FDCPmix cells were inoculated onto subconfluent irradiated $(20 \mathrm{~Gy})$ virusproducer cell lines. Various FDCPmix cell lines were used. Two days later, the loosely adherent cells and cells in suspension were harvested, washed, and resuspended at about $10^{5}$ cells $/ \mathrm{ml}$. After 2 days of culture, G418 was added to a final concentration of $1 \mathrm{mg} / \mathrm{ml}$ and the cells were subcultured as appropriate. Non-virus-infected cells died within 7 days but cells which had been co-cultured on the $\mathrm{M} 3 \mathrm{MuV}$ and $\mathrm{M} 3$ neo-producer cell lines continued to proliferate in the presence of the G418. About 2 weeks after selection with $\mathrm{G} 418$, the cells were cloned in soft agar in the presence of Il-3, and individual colonies were isolated and expanded from three different FDCPmix cell lines.

\section{Determination of Il-3 Activity}

M3-MuV infected cells $\left(10^{6}\right)$ were washed twice to remove residual Il-3 and incubated without WEHI-CM for $48 \mathrm{~h}$. The supernatant was used as such or concentrated tenfold via Amicon filtration (exclusion mol. wt. <10000), dialyzed, and tested for stimulatory activity on indicator cell lines by determining $\left[{ }^{3} \mathrm{H}\right]$ thymidine incorporation. Half-maximal stimulation of FDCP2 cells by either WEHI-CM or recombinant murine Il-3 was defined as $50 \mathrm{U} / \mathrm{ml}$.

\section{Growth Inhibition Assay}

One of the clones of FDCPmix infected with $\mathrm{M} 3 \mathrm{MuV}$ was grown at high density in the absence of Il-3. Cells were washed twice in medium without Il-3 and plated, $1 \times 10^{4}$ cells/well, into 96-well plates. Dilutions of the antiserum of preimmune rabbit serum ranged from 1:20 to $1: 10240$ final. $30 \mathrm{~h}$ after initiation, $0.5 \mu \mathrm{Ci}\left[{ }^{3} \mathrm{H}\right]$ thymidine was added for $14 \mathrm{~h}$. Cells were harvested onto filters, using a cell harvester (Titertec), and counted.

\section{Colony Assay}

$10^{3}$ control uninfected cells and cells infected with M3neo virus alone or $\mathrm{M} 3 \mathrm{MuV}$ were plated in soft agar in culture conditions which allow the expression of multiple hematopoietic lineages [19]. Individual colonies were isolated after 10 days of growth, cytospin preparations made, and the cells stained with benzidine plus May-Grunwald Giemsa. At least 30 colonies were examined from each group.

\section{Marrow Stromal Cell Culture}

Stromal cell cultures derived from bone marrow were irradiated $[20,21]$ and used as a supportive stroma for the growth of the FDCPmix cells, either uninfected, or $\mathrm{M} 3 \mathrm{MuV}$ or $\mathrm{M} 3$ neo infected. Between $2 \times 10^{6}$ and $10^{7}$ FDCPmix cells were cocultured with the marrow stromal cells. At various times after seeding of marrow stroma by the FDCPmix cells, cytospin preparations of the nonadherent cells were performed and the cells stained with May-Grunwald Giemsa.

\section{Diffusion Chamber Culture}

After two washes, aliquots of $5 \times 10^{5}$ FDCPmix cells, infected with either $\mathrm{M} 3 \mathrm{MuV}$ or $\mathrm{M} 3 \mathrm{Neo}$, were inoculated into each diffusion chamber (DC). These were then inserted intraperitoneally into male CBA mice. After 7 days of culture the animals were killed; the chambers were removed and shaken for $40 \mathrm{~min}$ in a $0.5 \%$ Pronase solution (Merck). The resulting cell suspensions were counted for 
the total number of nucleated cells. Cytospin preparations were made and the cells were classified according to morphological criteria [12].

\section{Nucleic Acid Analysis}

Cellular DNA was isolated and restricted by standard techniques and separated on agarose gels. Total RNA was isolated as previously described [2] and transferred to Gene Screen Plus (NEN) after denaturation with glyoxal and dimethylsulfoxide and electrophoresis through agarose gels [14]. Nucleic acids were transferred to Gene Screen Plus (NEN) and hybridized under the conditions recommended by the manufacturer, with probes labeled as previously described [4]. Probes used for analysis included an EcoRI-NcoI fragment of pMu21A containing the Il-3 cDNA clone (N. Gough, unpublished), the $B g l$ III-Bam HI fragment of pAG60 containing the coding region of the neo gene [3], and the PY80B probe specific for the murine Y-chromosome [1].

\section{$X$. In Vivo Administration of FDCPmix Cells}

Uninfected and A4/M3neo cells (cultured with Il-3) and A4/M3MuV cells (cultured without Il-3) were suspended in Fischer's medium at an appropriate cell concentration. The cells were injected i.v. in syngeneic B6D2Fl mice that had received $10 \mathrm{~Gy}$, prior to inoculation of the cells.

\section{Results}

I. Virus Integration, Gene Expression, and Il-3 Secretion

Following infection and selection in liquid culture the cells were cloned in soft agar in the presence of G418. Individual clones were isolated and cultured for further analysis. Analysis of the virus insertion sites revealed that the resulting cell lines were monoclonal (data not shown). The Il-3 gene was expressed in the MuV- infected FDCPmix cells, as shown by Northern analysis (data not shown). Conditioned medium of the M3MuV-infected cells growing in the absence of Il-3 contained between 4 and 50 units of I1-3 activity per $\mathrm{ml}$.

\section{Density-dependent Growth Autonomy}

All M3MuV infected cell lines could grow in high density without I1-3, whereas the uninfected FDCPmix cells and the M3neo-infected cells died in the absence of growth factor. Cloning of FDCPmix $\mathrm{M} 3 \mathrm{MuV}$-infected cells in soft agar resulted in nonlinear, density-dependent growth in the absence of Il-3 and in nearly linear growth in the presence of Il-3 (Fig. 1). Growth of the M3MuV-infected cells could be blocked by neutralizing antisera to Il-3 (Fig. 2).

\section{Differentiation Induction}

$\mathrm{M} 3 \mathrm{MuV}$-infected stem cell lines retained their capacity to undergo differentiation in response to serum factors or marrow

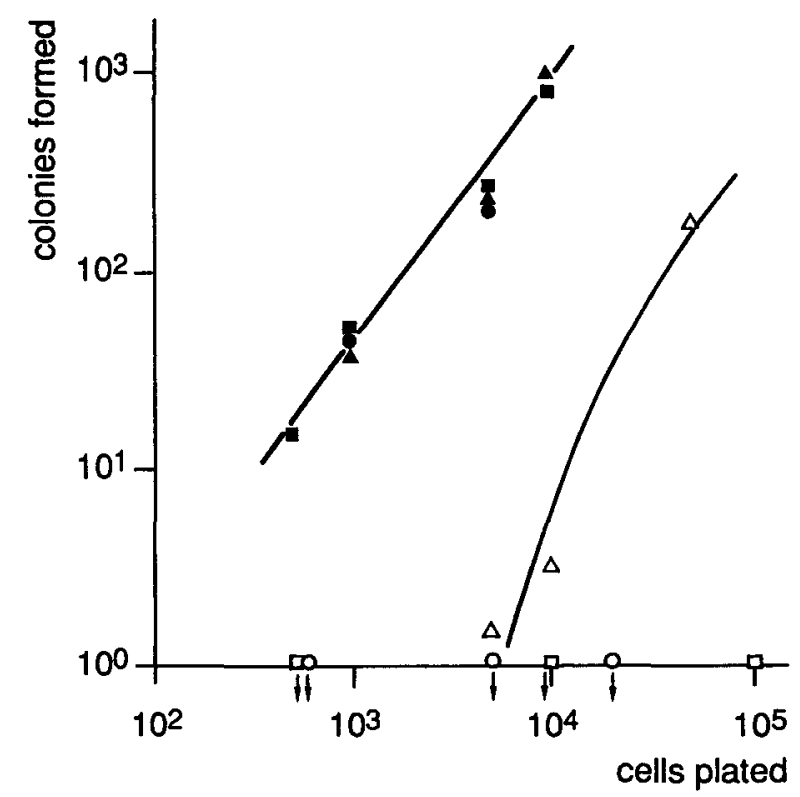

Fig. 1. Clonability of FDCPmix M3MuV-infected cells as a function of cell density. Uninfected FDCPmix cells with ( $\square$ ) and without ( $(\square)$ Il-3; M3neo-infected FDCPmix cells with (•) and without (o) I1-3; M3MuV-infected FDCPmix cells with $(\Delta)$ and without $(\Delta)$ Il-3 
Table 1. Colony formation by control and infected FDCPmix cells

\begin{tabular}{lllrlrr}
\hline & \multicolumn{7}{l}{ Colony morphology (\%) } \\
\cline { 2 - 7 } & PE (\%) & B & EG & LG & Mono & Mixed/Erythroid \\
\hline Uninfected cells & 6 & 9 & 4 & 63 & 8 & 16 \\
FDCP $_{\text {mix }} / \mathrm{M} 3$ neo & 8 & 11 & 7 & 59 & 10 & 13 \\
FDCP $_{\text {mix }} / \mathrm{M} 3 \mathrm{MuV}$ & 7 & 45 & 31 & 18 & 6 & $<1$ \\
\hline
\end{tabular}

PE (\%), Plating efficiency, i.e., number of colonies formed per 100 cells plated; B, primitive blast cells; EG, promyelocytes and myelocytes; LG, metamyelocytes and mature granulocytes (including eosinophils); Mono, large mononuclear cells

Table 2. In vivo administration of FDCPmix cells

\begin{tabular}{|c|c|c|c|c|c|}
\hline Group & $\begin{array}{l}\text { Cells } \\
\text { injected }\end{array}$ & $\begin{array}{l}\text { No. of } \\
\text { animals } \\
\text { leukemic* }\end{array}$ & $\begin{array}{l}\text { Spleen } \\
\text { weight } \\
\text { (mg, range) }\end{array}$ & $\begin{array}{l}\text { Blood counts } \\
\left(\times 10^{-3} / \mathrm{mm}^{3},\right. \\
\text { range })\end{array}$ & $\begin{array}{l}\text { Femur } \\
\text { cellularity } \\
\left(\times 10^{-7}, \text { range }\right)\end{array}$ \\
\hline Uninfected & $10^{7}$ & $0 / 20$ & $80-120$ & $3-$ & $1.2-2.3$ \\
\hline $\mathrm{FDCP}_{\text {mix }} / \mathrm{M} 3$ neo & $10^{7}$ & $0 / 10$ & $70-110$ & $3-7$ & $1.3-2.2$ \\
\hline $\mathrm{FDCP}_{\text {mix }} / \mathrm{M} 3 \mathrm{MuV}$ & $5 \times 10^{6}$ & $15 / 15$ & $530-1164$ & $40-276$ & $0.7-1.1$ \\
\hline
\end{tabular}

* Morbidity was first observed 6 weeks after injection of the cells, and the majority of the animals had developed clear evidence of hematopoietic disease (and were autopsied accordingly) within 12 weeks

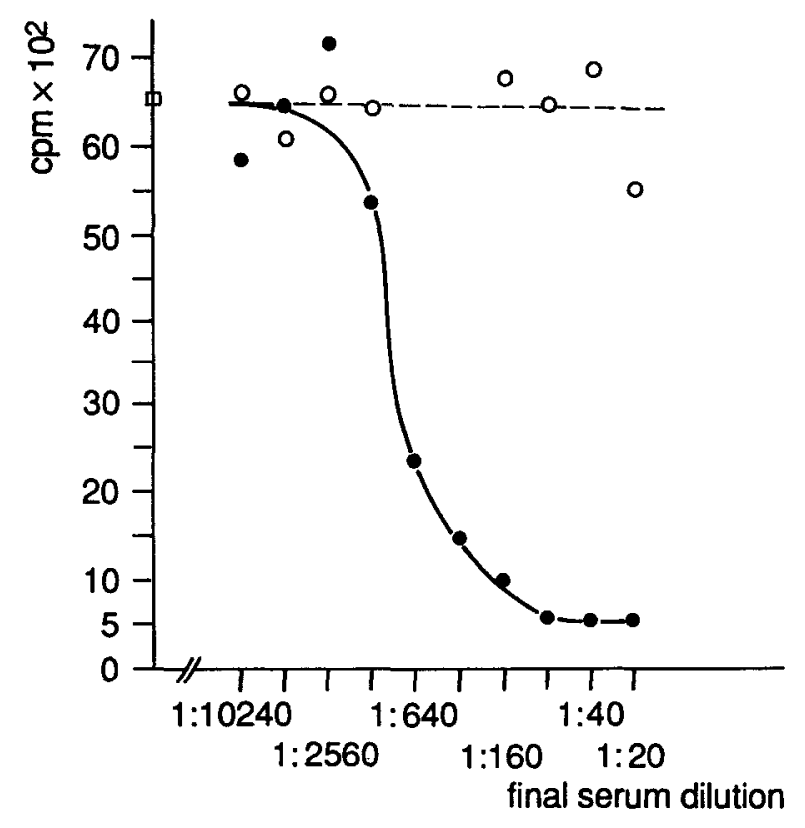

Fig. 2. Growth inhibition of FDCPmix M3MuV-infected cells by anti-Il-3 antiserum. - Growth medium with rabbit anti-Il-3 antiserum; o growth medium with rabbit preimmune serum; $\square$ growth medium without antiserum or preimmune serum stromal cells. In the mixed colony assay the plating efficiency was unaltered and the colonies produced contained maturing granulocytes and macrophages (Table 1). However, erythroid cells were rarely seen, and the balance between immature and mature granulocytes was changed in favor of immature cells (Table 1, Fig. 3). The same was true when the cells were co-cultured with marrow stromal cells (data not shown). Culture of $\mathrm{M} 3 \mathrm{MuV}$-infected FDCPmix cells in vivo in the DC led to an increase of immature and mature granulocytes and macrophages similar to the in vitro observations. In addition, erythroblasts were also found in the DC (data not shown).

\section{In Vivo Administration of FDCPmix MuV-infected Cells}

When FDCPmix M3MuV-infected cells were injected into sublethally irradiated 
Fig. 3a, b. Mixed colony formation by control and infected FDCPmix cells. a Parental FDCPmix cells; b FDCP. mix M3MuV-infected cells

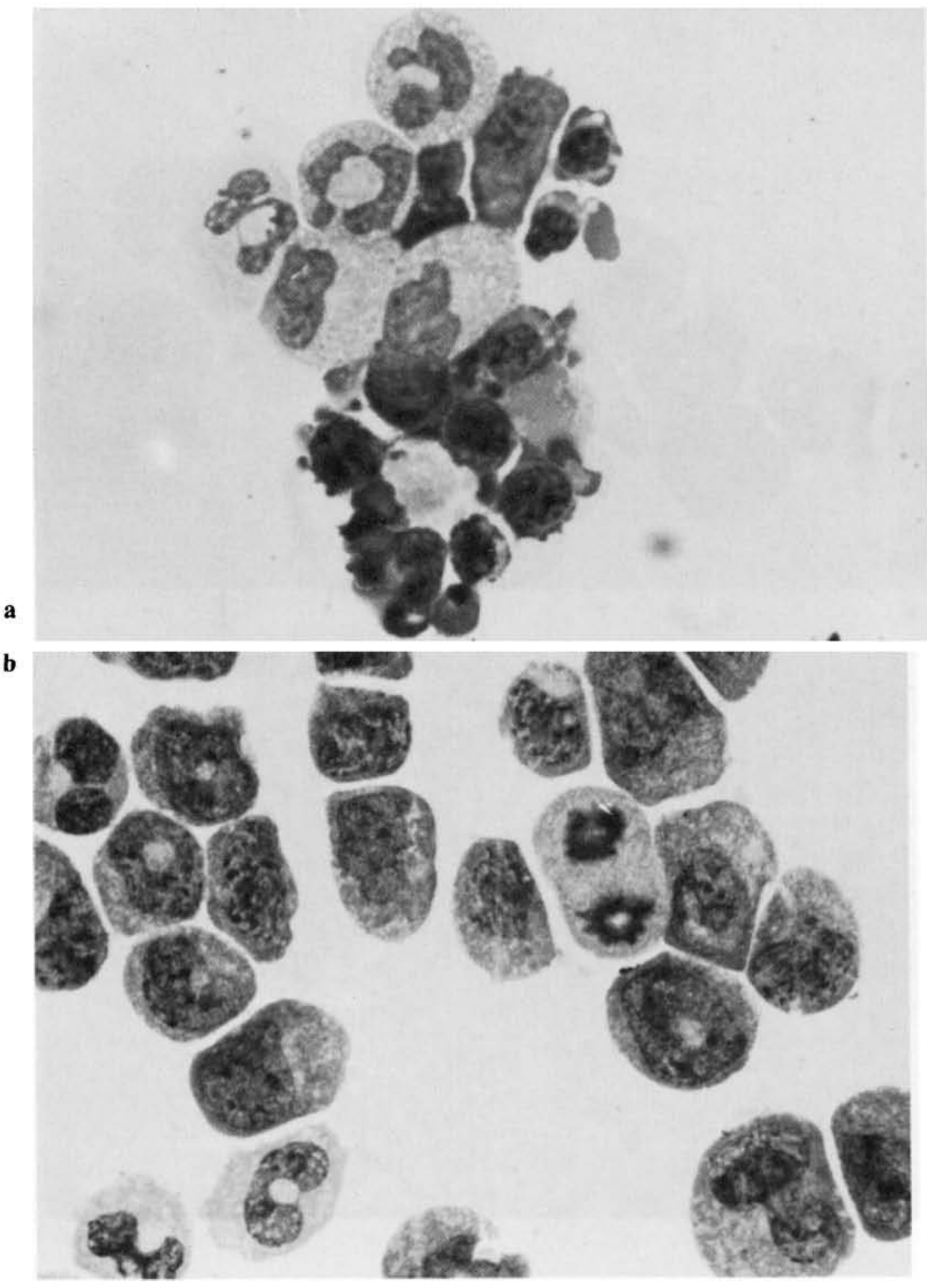

syngeneic mice, the animals developed a five- to ten fold increase in the spleen weight, an increase in peripheral leukocytes, and a decreased hematocrit (Table 2). Morphological analysis of cells present in the spleen and peripheral blood of a representative mouse (Fig. 4) showed the following differential: spleen (blood) $16 \%$ (2) $\%$ blasts, $21 \%$ (10) $\%$ promyelocytes/myelocytes, $55 \%$ (75)\% metamyelocytes and polymorphonuclear granulocytes, $5 \%$ (1) $\%$ nucleated erythroid cells, $3 \%(12) \%$ other. The animals died within 2 months, whereas control mice, in-

jected with stem cells containing the M3neo vector, showed no evidence of disease 6 months later. To determine the origin of the disease, cytogenetic analysis of cells in the spleen of the leukemic mice was performed. Initially, $80 \%-100 \%$ of the mitoses were of donor origin and possessed a normal (donor) male karyotype. Subsequently, however, spleen, bone marrow, and blood cells were of recipient origin, as revealed by Southern blotting (data not shown). Furthermore, the viral integration sites of cell lines recovered from leukemic animals were different 

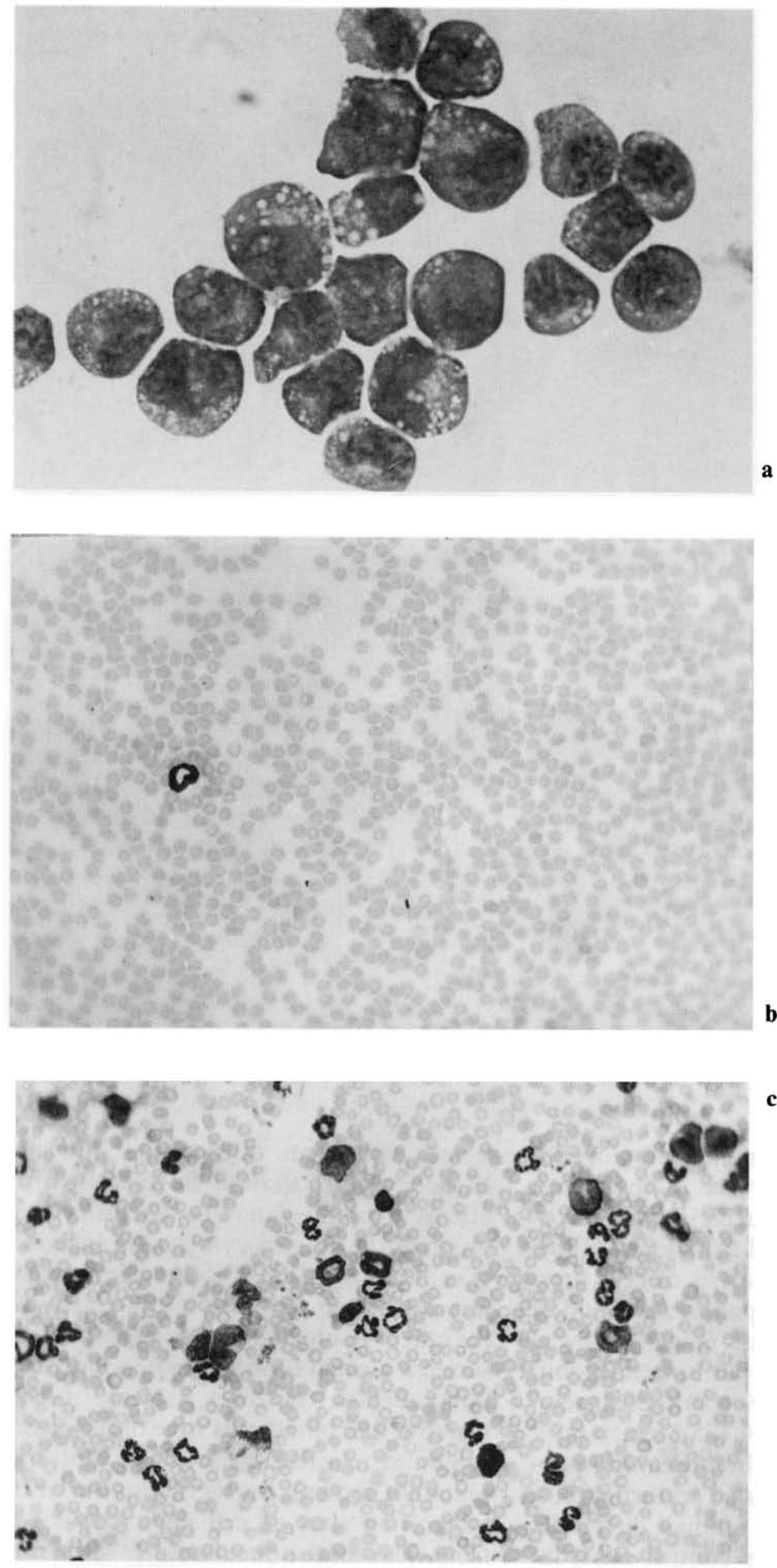

c

Fig. $4 \mathrm{a}-$ d. In vivo administration of FDCPmix M3MuVinfected cells. a FDCP-mix M3MuV-infected cells; b normal peripheral blood cells; c peripheral blood cells from leukemic mouse; $\mathbf{d}$ spleen cells from leukemic mouse 


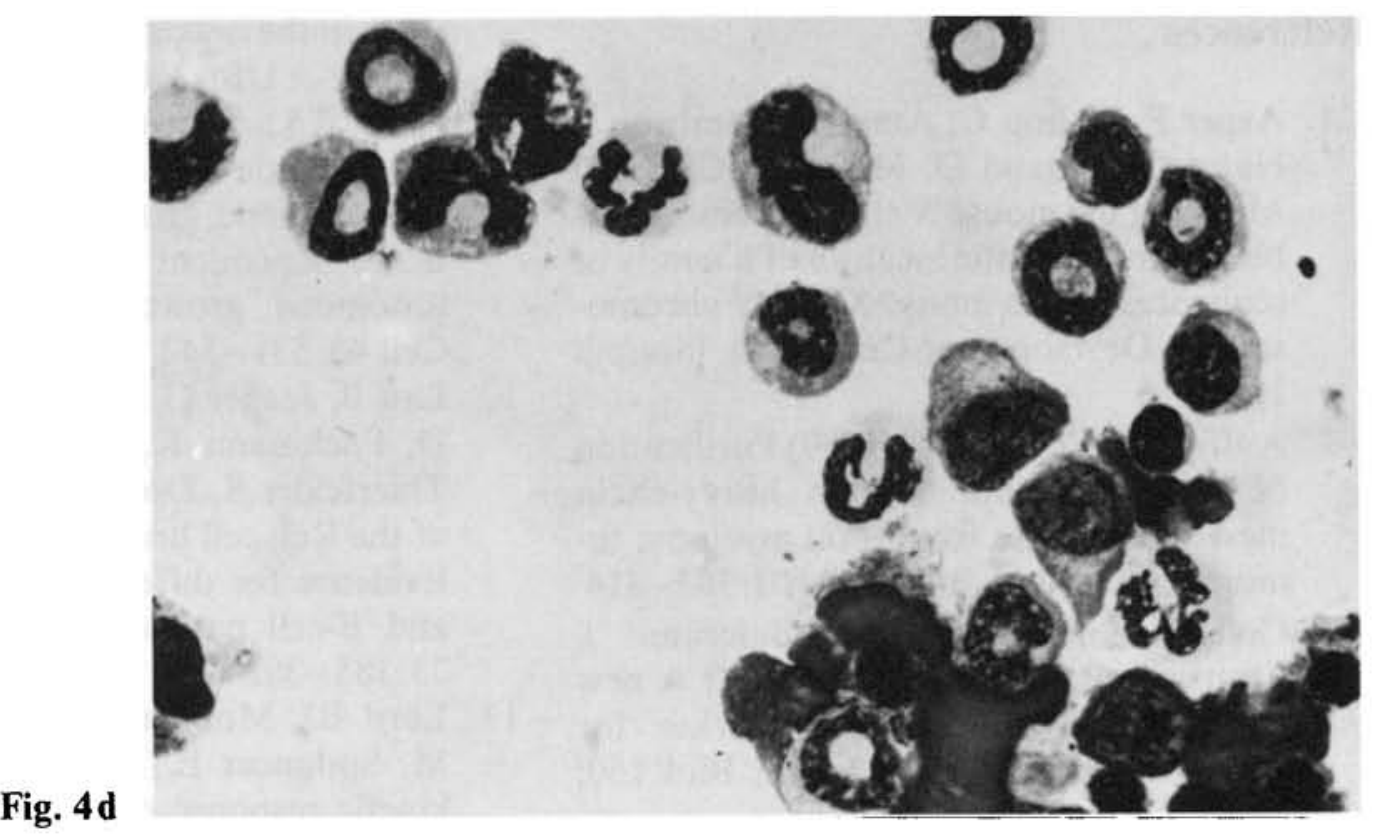

from the original viral insertion site of the donor FDCPmix cells (data not shown).

\section{Discussion}

The present results show that infection of multipotent Il-3-dependent stem cells with a retroviral vector containing the Il-3 gene confer density-dependent autocrine stimulation of growth without blocking differentiation, but with a change of the balance between differentiation and proliferation in favor of proliferation. From these data we conclude that inappropriate expression of Il-3 may play an important role in the multistep pathogenesis of leukemia. When the Il-3 infected cells were injected into sublethally irradiated syngeneic mice, the animals developed a myeloproliferative disease. However, the precise role of the injected cells remains to be determined. Analysis of spleen and blood cells of the leukemic mice revealed that the proliferating cells were initially derived from the transplanted stem cells but were subsequently of recipient origin. Furthermore, the viral integration sites in cell lines recovered from leukemic animals showed different bands as compared with the original injected cells, indicating infection of host cells. Since FDCPmix cells contain an ecotropic helper virus (MoMuLV) [23], it could have packaged the defective MuV vector to produce an infectious virus which may then have transformed host cells. However, when high levels of the original $\mathrm{MuV}$ virus are injected into mice no myeloproliferative disease is observed [9]. In the latter case, this may reflect a difficulty in the ability of the injected virus to "target" to the host cells in the sites of active hematopoiesis. This may not be the case for the MuV-infected FDCPmix cells, which can clearly lodge in the spleen and bone marrow and may be acting as "carriers" for infectious viral particles, thus facilitating infection of host hematopoietic cells. Also, it has been reported that injection of recombinant Il-3 into normal mice leads to an increase in spleen weight and content of CFU-S, as well as to an increase in progenitor cells of the myeloid lineage $[8,13$, 15]. Therefore, Il-3 production by the infected cells (both donor and host) may have contributed to the disease by stimulating stem and progenitor cells from the recipient mice. Thus, the disease is probably multifactorial. Nonetheless, we have clearly shown that endogenous inappropriate expression of a growth factor gene can have profound biological effects and may well be a part of the process leading to leukemic transformation. 


\section{References}

1. Avner P, Bishop C, Amar L, Cambrou J, Hatat D, Arnaud D, Mattei M-G (1987) Mapping the mouse $X$ chromosome possible symmetry in the location of a family of sequences on the mouse $\mathrm{X}$ and $\mathrm{Y}$ chromosomes. Development-Camb 101 [Suppl]: $107-116$

2. Auffray C, Rougeon F (1980) Purification of mouse immunoglobulin heavy-chain messenger RNAs from total myeloma tumor RNA. Eur J Biochem 107:303-314

3. Colbere-Garapin F, Horodniceanu J, Kourilsky P, Garapin A-C (1981) A new dominant hybrid selective marker for higher eukaryotic cells. J Mol Biol 150: $1-14$

4. Feinberg AP, Vogelstein B (1984) A technique for radiolabeling DNA restriction endonuclease fragments to high specific activity. Anal Biochem 137:266-267

5. Fialkow PJ, Singer JW (1985) Tracing development and cell lineages in human hemopoietic neoplasia. In: Weissman IL (ed) Leukemia. Dahlem Workshop. Springer, Berlin Heidelberg New York, pp 202-222

6. Fialkow PJ, Singer JW, Adamson JW, Vaidya K, Dow LW, Ochs J, Moohr JW (1981) Acute nonlymphocytic leukemia: heterogeneity of stem cell origin. Blood 57:1068-1073

7. Greaves MF, Delia D, Robinson J, Sutherland R, Newman R (1981) Exploitation of monoclonal antibodies: a "who's who" of haemopoietic malignancy. Blood Cells $7: 257-280$

8. Kindler V, Thorens B, de Kossodo S, Allet B, Eliason JF (1986) Stimulation of hematopoiesis in vivo by recombinant bacterial murine interleukin 3. Proc Natl Acad Sci USA 83: $1001-1005$

9. Laker C, Kluge N, Stocking C, Just U, Franz M-J, Ostertag W, Dexter M, Katsuno M, Spooncer E (1989) Leukemogenesis initiated by aberrant multi-CSF expression is a multi-step process and differs in hematopoietic stem and precursor cell lines. Mol Cell Biol (in press)

10. Laker C, Stocking C, Bergholz U, Hess N, DeLamarter JF, Ostertag W (1987) Autocrine stimulation after transfer of the granulocyte/macrophage colony-stimulating factor gene and autonomous growth are distinct but inter-dependent steps in the oncogenic pathway. Proc Natl Acad Sci USA 84: 8458-8462

11. Lang RA, Metcalf D, Gough N, Dunn AR, Gonda TJ (1985) Expression of a haemopoietic growth factor cDNA in a factor-dependent cell line results in autonomous growth and tumorigenicity. Cell 43:531-542

12. Lau B, Jaeger G, Thiel E, Rodt H, Huhn D, Pachmann K, Netzel B, Boening L, Thierfelder S, Doermer P (1979) Growth of the Reh cell line in diffusion chambers. Evidence for differentiation along the $\mathrm{T}$ and B-cell pathway. Scand J Haematol 23: $385-392$

13. Lord BJ, Molineux G, Testa NG, Kelly M, Spooncer E, Dexter TM (1986) The kinetic response of haemopoietic precursor cells, in vivo, to highly purified, recombinant interleukin-3. Lymphokine Res 5:97-104

14. McMaster GK, Carmichael GG (1977) Analysis of single- and double-stranded nucleic acids on polyacrylamide and agarose gels by using glyoxal and acridine orange. Proc Natl Acad Sci USA 74: 4835-4839

15. Metcalf D, Begley CG, Johnson GR, Nicola NA, Lopez AF, Williamson DJ (1986) Effects of purified bacterially synthesized murine multi-CSF (IL-3) on hematopoiesis in normal adult mice. Blood 68: $46-57$

16. Miller AD, Buttimore C (1986) Redesign of retrovirus packaging cell lines to avoid recombination leading to helper virus production. Mol Cell Biol 6:2895-2902

17. Rowley JD (1985) Significance of chromosome rearrangements in leukaemia and lymphoma. In: Weissman IL (ed) Leukemia. Dahlem Workshop. Springer, Berlin Heidelberg New York, pp 179-202

18. Roberts RA, Spooncer E, Parkinson EK, Lord BI, Allen TD, Dexter TM (1987) Metabolically inactive 3T3 cells can substitute for marrow stromal cells to promote the proliferation and development of multipotent haemopoietic stem cells. $\mathbf{J}$ Cell Physiol 132: 203-214

19. Spooncer E, Boettiger D, Dexter TM (1985) Continuous in vitro generation of mulitpotential stem cell clones from srcinfected cultures. Nature 310:228-230

20. Spooncer E, Heyworth CM, Dunn A, Dexter TM (1986) Self-renewal and differentiation of interleukin-3-dependent multipotent stem cells are modulated by stro- 
mal cells and serum factors. Differentiation 31:111-118

21. Spooncer E, Lord BI, Dexter TM (1985) Defective ability to self-renew in vitro of highly purified primitive haematopoietic cells. Nature 316:62-64

22. Stocking C, Kollek R, Bergholz U, Ostertag W (1985) Long terminal repeat sequences impart hematopoietic transformation properties to the myeloprolifera- tive sarcoma virus. Proc Natl Acad Sci USA 82:5746-5750

23. Wyke JA, Stoker AW, Searle S, Spooncer E, Simmons P, Dexter TM (1986) Perturbed hemopoiesis and the generation of mulitpotential stem cell clones in src-infected bone marrow cultures is an indirect or transient effect of the oncogene. Mol Cell Biol 6:959-963 